\title{
Current Trends in Sport Climbing Injuries after the Inclusion into the Olympic Program. Analysis of 633 Injuries within the years 2017/18
}

\author{
C. Lutter ${ }^{1}$, T. Tischer ${ }^{1}$, T. Hotfiel ${ }^{2}$, L. Frank ${ }^{3}$, A. Enz ${ }^{1}$, M. Simon ${ }^{4}$, V. Schöff $\mid 3,4,5,6$ \\ 1 Department of Orthopedics, University Medical Center, Rostock, Germany \\ 2 Department of Orthopedics, University Medical Center, Erlangen, Germany \\ 3 Department of Trauma Surgery, Friedrich Alexander University Erlangen-Nuremberg, Germany \\ 4 Department of Sports Orthopedics, Sports Medicine, Sports Traumatology, Klinikum Bamberg, Germany \\ 5 Section of Wilderness Medicine, Department of Emergency Medicine, University of Colorado School of \\ Medicine, Denver, USA \\ 6 School of Clinical and Applied Sciences, Leeds Becket University, Leeds, UK
}

\section{CORRESPONDING AUTHOR:}

Christoph Lutter

Department of Orthopedics

University Medical Center

Rostock

Doberaner Straße 146

18057 Rostock, Germany

E-mail: christoph.lutter@

googlemail.com

DOI:

10.32098/mltj.02.2020.06

LEVEL OF EVIDENCE: 4

\begin{abstract}
SUMMARY
Objective. To prospectively evaluate current demographics, distribution and severity of rock climbing-related injuries after the sport's inclusion into the Olympic program and to analyze changes in comparison to two prior study populations.

Methods. In 2017-2018, we performed a single-center injury survey including 436 climbing patients with a total number of 633 independent climbing-related injuries or complaints.

Results. $77.1 \%$ of the injuries affected the upper extremities, $17.7 \%$ the lower and $5.2 \%$ other body regions. Injury severity was overall low (Union Internationale des Associations d'Alpinisme (UIAA) metric scale: $1.8 \pm 1(1-4))$. The most frequent injuries were finger pulley injuries $(12.3 \%)$ and finger tenosynovitis (10.6\%). $43.9 \%$ of reported injuries were acute and $56.1 \%$ were chronic. Bouldering accidents were the leading cause of acute injuries $(60.4 \%)$. Among shoulder injuries, superior labral lesion tears from anterior to posterior (SLAP) represented the leading diagnosis (29.8\%). In comparison to our two prior study populations (1998-2001 and 2009-2012), we found: 1) an overall decrease in upper extremity injuries, 2) an increase of lower extremity injuries, 3) a constant decrease of finger pulley injuries and epicondylitis, 4) a rise of knee injuries and shoulder dislocations, 5) an increase of adolescents finger growth plate injuries.

Conclusions. Severity of climbing injuries is low overall. Distinct trends are noticeable: being that some injury rates rose while others fell, preventative strategies only seem partially effective. Therefore, adjustment of preventive strategies is required.
\end{abstract}

\section{KEY WORDS}

Olympia; bouldering; speed; lead; injury surveillance

\section{INTRODUCTION}

Rock climbing experienced a rapid increase in popularity over the last few years and will be presented as a new Olympic discipline during the Olympic Games in Tokyo 2020 (1). With the introduction of modern climbing styles and the inclusion of climbing into the Olympic program, the sport has experienced massive changes in terms of professionalization, public attention, and number of sports enthusiasts. While several studies on injury demographics and severity have been published, recently, several studies reported injury mechanisms and specifications which have been rarely seen in the past-indicating a change in injury demograph- ics, distribution and severity (10-12). Various authors attribute the rise in new climbing injury patterns and change in injury distribution to modern steep and three-dimensional wall architecture, trends in route setting, and the wave of untrained beginners within the sport $(1,2,12)$.

Moreover, we recently argued that recent demographic changes in climbing participation have brought up sport specific injury patterns (e.g. knee injuries) that were rarely seen in the past $(1,2)$. Until today, studies have shown, that overuse injuries in climbing mainly affect the upper extremity, whereas, acute trauma predominantly occurs at the lower extremity (3-8). There are many different subdis- 
ciplines in rock climbing (e.g. Bouldering, Alpine-, Speed Climbing); the new trend is to enjoy the easy availability of indoor climbing and bouldering gyms (2). Various studies analyzing injury severity of different climbing subdisciplines have indicated a low injury rate in those two subdisciplines of rock climbing (9).

The assessment of current trends and distributions of injuries can emphasize further preventive strategies and allow a continued assessment of the previous preventive measures.

To evaluate current demographics, distribution, and severity of rock climbing related injuries since its inclusion into the Olympic program, we conducted a clinical follow-up study, allowing direct comparison to two prior study populations $(14,15)$.

\section{METHODS}

From January $1^{\text {st }}, 2017$ to December $31^{\text {st }}, 2018$, all patients that presented at our clinic complaining of acute or overuse injuries caused by rock climbing and/or bouldering were assessed (table I). The study was approved by the institutional review board and all patients provided informed consent. Athletes were seen and treated in our specialized out-patient sports medicine clinic which is a referral center for climbing related injuries (e.g. German Alpine Club). Diagnoses were made based on clinical investigation and radiological findings by three experienced orthopedic surgeons (MS, CL, VS) in the field of climbing-related injuries. All final diagnoses were reviewed and confirmed by

Table I. Patient injury distribution and grading 2017-2018 compared with two prior studies $(14,15)$.

\begin{tabular}{|c|c|c|c|}
\hline Patients & $2017-2018(n=436)$ & $2009-2012(n=836)$ & $1998-2001(n=604)$ \\
\hline Number of injuries & 633 & 911 & 604 \\
\hline Age, years & $30.8 \pm 11.2(8-67)$ & $34.1 \pm 11.1(11-77)$ & $28.3 \pm 12.4(13-52)$ \\
\hline Climbing level (UIAA metric) & $8.6 \pm 1.2(4.3-12)$ & $8.8 \pm 1.2(5.0-11.3)$ & $8.6 \pm 1.1(5.3-11.0)$ \\
\hline Bouldering level (V-scale) & $5.7 \pm 4.0(0-15)$ & - & - \\
\hline Height $(\mathrm{cm})$ & $175 \pm 9.5(130-197)$ & - & - \\
\hline Weight $(\mathrm{kg})$ & $67.5 \pm 11.7(28-102)$ & - & - \\
\hline Body mass index & $21.9 \pm 2.4(15.2-34.9)$ & - & - \\
\hline Women & $20.6 \pm 2.3(15.9-31.8)$ & - & - \\
\hline Lower extremity & $112(17.7)$ & $58(6.4)$ & $77(12.7)$ \\
\hline Other & $33(5.2)$ & $20(2.2)$ & $122(20.2)$ \\
\hline Injury grading & $1.8 \pm 1(1-4)$ & & \\
\hline UIAA 1 & $131(20.1)$ & $17(1.9)$ & $4(0.6)$ \\
\hline UIAA 2 & $461(72.1)$ & $881(96.7)$ & $584(96.7)$ \\
\hline UIAA 3 & $40(6.3)$ & $13(1.4)$ & $9(1.5)$ \\
\hline UIAA 4 & $1(0.1)$ & None & $7(1.2)$ \\
\hline UIAA 5-6 & None & None & None \\
\hline \multicolumn{4}{|l|}{ Injury type } \\
\hline
\end{tabular}


the senior author (VS). Patients with acute injuries initially seen and treated in the emergency department of our 24-hour, level 1 trauma center were later re-examined in the out-patients sports medicine clinic. The clinic is one of three trauma centers of Germany's biggest outdoor sport-climbing and bouldering areas, the Frankenjura. A standard questionnaire, which included questions about medical history, and a physical examination protocol were conducted on all patients. Only patients suffering from pain during or after climbing were included in the study. Injuries caused by rock climbing or bouldering activities were defined as medical conditions forcing the athlete to rest from his/her sport due to pain or dysfunction and the necessity to seek help from a physician. While acute injuries were defined as injuries with a sudden onset during climbing without any prior history of complaints, overuse injuries were defined as chronic injuries without a singular causing event or a specific trauma that had developed during or after climbing. The Union Internationale des Associations d'Alpinisme (UIAA) metric scale was used for evaluation of climbing levels as in two previous studies from our center (years 1998-2001: 604 climbing injuries; and 2009-2012: 911 climbing injuries) (14, 15). Injuries were graded according to the UIAA injury score. The orchard sports injury classification system 10 (OSICS 10) scale was used to categorize the injury distribution following the Union Internationale des Associations d'Alpinisme (UIAA) MedCom recommendation $(13,16)$.

Microsoft Excel (Microsoft, Redmond, Washington, USA) was used for data collection; statistical analyses were performed using SigmaStat software (Systat Software Inc., San Jose, USA). Values were checked for normality with the Shapiro-Wilk test. To determine the difference between the groups, a t-test or rank-sum test was used depending on normal distribution. P-values $<0.05$ were considered as statistically significant.

\section{RESULTS}

In 2017 and 2018, 436 patients were treated with 633 independent injuries caused by rock climbing or bouldering (table I). Of the 436 patients, 197 patients had two injuries within the study period. Among the 633 injuries, 355 $(56.1 \%)$ were overuse injuries and $278(43.9 \%)$ were acute injuries. The acute injury mechanism rates were bouldering $(60.4 \%)$, rock climbing $(31.7 \%)$ and other (e.g. hangboard training, $7.9 \%$ ) (table I). The upper extremity was affected in $77.1 \%$, the lower extremity in $17.7 \%$ and the head, neck and trunk in $5.2 \%$ of all cases. For detailed information on injury distribution, see tables I-III and figure 1. The mean climbing level (UIAA $8.6 \pm 1.2$ (4.3-
12)) was constant as compared to the two prior study populations (1998-2001: mean UIAA grade 8.6; 20092012: mean UIAA grade 8.8) (table I). Localizations of injuries following the OSICS 10 score are presented in table III (13). Table IV provides a comparison of the injury distribution (ten most frequent injuries), as previously published (table IV, figure 2). Finger injuries represented $41.2 \%$ of all injuries and shoulder injuries accounted for $20.2 \%$. Hand injuries $(7.7 \%)$, forearm/elbow pathologies $(7.7 \%)$ and lower leg/foot injuries $(10.6 \%)$ were diagnosed less often (table II, figure 1). Finger pulley injuries represented $12.3 \%$ of all injuries and accounted for $29.9 \%$ of all finger injuries. This diagnosis was the most frequently seen injury in the study group, followed by finger tenosynovitis $(10.6 \%)$, and finger joint capsulitis $(7.7 \%$ ) (Table 4). Overall, 17 different diagnoses of finger injuries were present (table V, figure 3). Among shoulder injuries, SLAP tears were found most frequently $(29.8 \%)$, followed by subacromial impingement syndromes $(27.4 \%)$ and dislocations/Bankart lesions $(17.7 \%)$ (table VI), The average UIAA injury score was $1.8 \pm 1(1-4)$. None of the athletes suffered a UIAA grade 5 injury and none of them died (UIAA 6) (Table 1). Climbing level (UIAA level, p=0.006) and climbing experience (climbing years, $\mathrm{p}=0.029$ ) were both significantly higher in men than in women. The difference in climbing levels was lower than in prior studies; mean female UIAA level was 8.33 and mean male UIAA level was 8.73 , respectively. Climbing levels showed a wider range than in the past, meaning that there was an increased number of both beginner athletes and worldclass athletes within the study population (table I).

In comparison with the two prior study periods, the main findings were: the upper extremity was less affected in the presented study population, whereas, lower extremity injuries were diagnosed more frequently $(14,15)$ (tables I-III). Finger pulley injuries consistently decreased from $20.2 \%(1998-2001)$ and $15.4 \%(2009-2012)$ to $12.3 \%$ in the current analysis (table IV). Similar findings were seen for epicondylitis, which currently represented only $3.3 \%$ (1998-2001: 8.4\%, 2009-2012: 5.5\%). Knee injuries, wrist strains and epiphyseal fractures of the finger were found to be among the ten most frequently diagnosed injuries, whereas, they were not seen frequently within the two prior studies (table IV). Epiphyseal fractures, which were seen in $0.8 \%$ of all cases between 1998-2001 and 3.4\% from 2009-2012, were present in $7.3 \%$ of all finger injuries within our athletes (tables IV and V). Among the shoulder pathologies, we found a rise of shoulder dislocations (2009-2012: 10.2\%, 2017-2018: 17.7\%) and acromioclavicular joint injuries (2009-2012: 1.9\%, 2017-2018: 9.7\%) (table VI). 
Table II. Injury distribution according to body area as presented previously (data of trunk, spine and pelvis merged). Values are $\mathrm{n}(\%)$.

\begin{tabular}{llll}
\hline Body area & $\mathbf{2 0 1 7 - 2 0 1 8 ~}(\mathbf{n}=\mathbf{6 3 3})$ & $\mathbf{2 0 0 9 - 2 0 1 2}(\mathbf{n}=\mathbf{9 1 1})$ & $\mathbf{1 9 9 8 - 2 0 0 1}(\mathbf{n}=\mathbf{6 0 4})$ \\
\hline Finger & $261(41.2)$ & $474(52)$ & $247(41)$ \\
\hline Shoulder & $128(20.2)$ & $157(17.2)$ & $30(5)$ \\
\hline Hand & $49(7.7)$ & $119(13.1)$ & $47(7.8)$ \\
\hline Forearm and elbow & $49(7.7)$ & $83(9.1)$ & $81(13.4)$ \\
\hline Lower leg/foot & $67(10.6)$ & $35(3.8)$ & $55(9.1)$ \\
\hline Knee & $45(7.1)$ & $19(2.1)$ & $22(3.6)$ \\
\hline Trunk, spine, pelvis & $34(5.4)$ & $21(2.3)$ & $43(7.1)$ \\
\hline Other & - & $3(0.3)$ & - \\
\hline
\end{tabular}

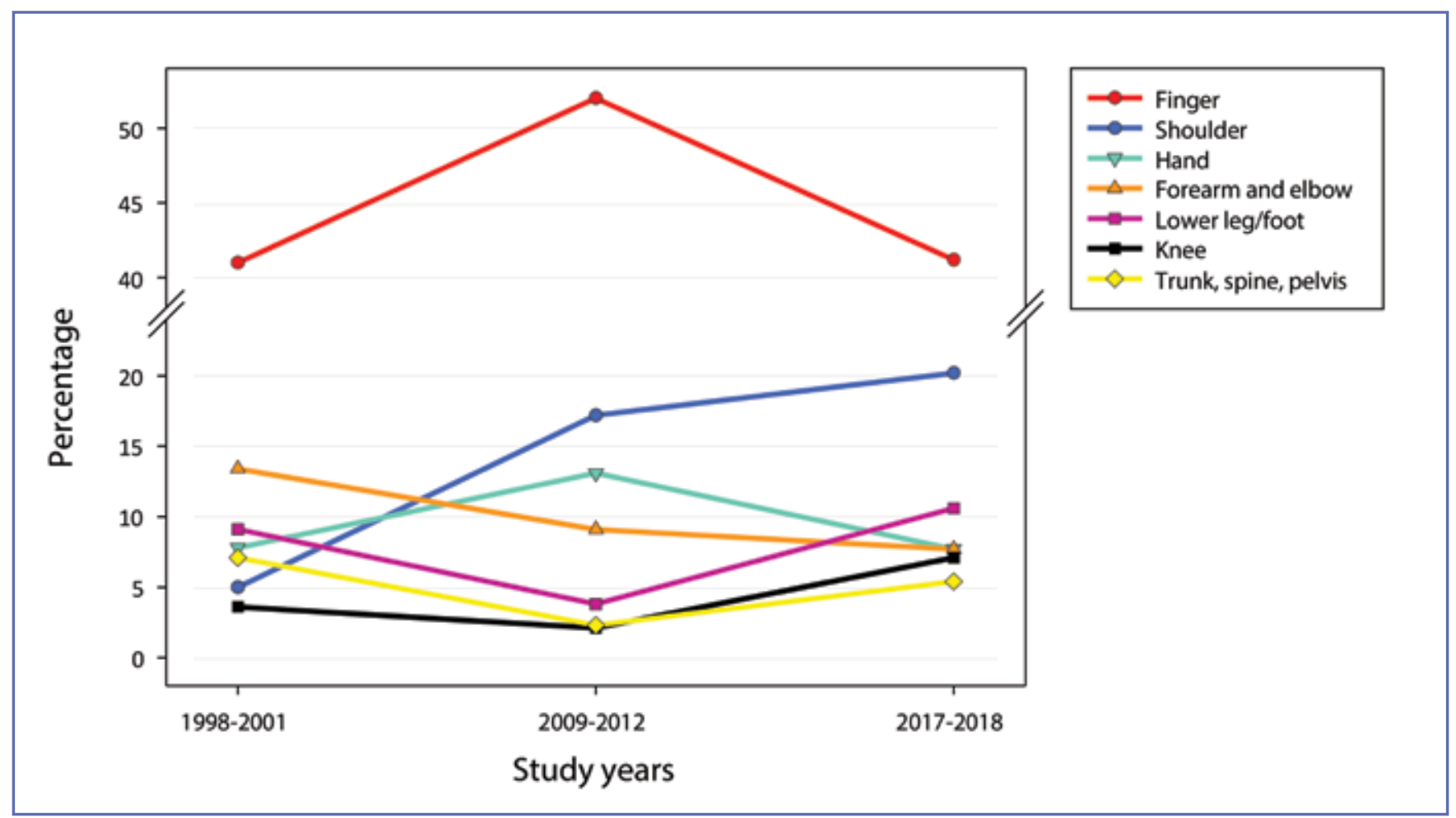

Figure 1. Injury distribution according to body area compared with two prior studies.

\section{DISCUSSION}

This study focuses on current trends and changes in rock climbing related injuries since its inclusion into the Olympic program for Tokyo 2020 (1). Two prior studies have been conducted with the same methods, allowing a direct comparison and interpretation of data $(14,15)$. The gap between the two first studies was 10 years, and 7 years have passed since the last (2009-2012). However, the world- wide rise of bouldering within the last 7-8 years, and the inclusion into the Olympics, has changed the sport rapidly $(12,17)$. On one hand, more and more athletes around the world are enthusiastic about rock climbing and bouldering, and on the other, the sport also professionalises rapidly (1). Our study population nicely represents both the changes, as more beginners and world-class athletes were among the patients than in our prior studies. Mean climbing levels were 
Table III. Anatomical sites according to Orchard Sports Injury Classification System 10 (OSICS). Values are n (\%). (Data 19982001 n.A.).

\begin{tabular}{|c|c|c|c|c|}
\hline Main grouping & Category & OSICS Designation & $2017-2018(n=633)$ & $2009-2012(n=911)$ \\
\hline \multirow[t]{2}{*}{ Head and neck } & Head/face & $\mathrm{H}$ & $1(0.2)$ & $0(0)$ \\
\hline & Neck/cervical spine & $\mathrm{N}$ & $3(0.5)$ & $4(0.4)$ \\
\hline \multirow[t]{6}{*}{ Upper limbs } & Shoulder/clavicle & $\mathrm{S}$ & $115(18.2)$ & $157(17.2)$ \\
\hline & Upper arm & $\mathrm{U}$ & $14(2.2)$ & $0(0)$ \\
\hline & Elbow & $\mathrm{E}$ & $39(6.2)$ & $70(7.7)$ \\
\hline & Forearm & $\mathrm{R}$ & $10(1.6)$ & $12(1.3)$ \\
\hline & Wrist & W & $32(5.1)$ & $69(7.6)$ \\
\hline & Hand/finger/thumb & $\mathrm{P}$ & $276(43.6)$ & $528(57.1)$ \\
\hline \multirow[t]{5}{*}{ Trunk } & Chest (sternum/ribs) & $\mathrm{C}$ & $2(0.3)$ & $0(0)$ \\
\hline & Thoracic spine & $\mathrm{D}$ & $5(0.8)$ & $0(0)$ \\
\hline & Trunk, abdomen & $\mathrm{O}$ & $2(0.3)$ & $0(0)$ \\
\hline & Lumbar spine & $\mathrm{B}$ & $9(1.4)$ & $11(1.2)$ \\
\hline & Pelvis and buttock & $\mathrm{L}$ & $7(1.1)$ & $2(0.2)$ \\
\hline \multirow[t]{6}{*}{ Lower limbs } & Hip/groin & G & $5(0.8)$ & $4(0.4)$ \\
\hline & Thigh & $\mathrm{T}$ & $6(0.9)$ & $0(0)$ \\
\hline & Knee & $\mathrm{K}$ & $45(7.1)$ & $19(2.1)$ \\
\hline & Lower leg & $\mathrm{Q}$ & $7(1.1)$ & $3(0.3)$ \\
\hline & Ankle & $\mathrm{A}$ & $39(6.2)$ & $12(1.3)$ \\
\hline & Foot/toe & $\mathrm{F}$ & $15(2.4)$ & $20(2.2)$ \\
\hline Location unspecified & & $\mathrm{X}$ & $1(0.2)$ & $0(0)$ \\
\hline
\end{tabular}

Table IV. Distribution of diagnoses (ten most frequent injuries).

\begin{tabular}{lllllllll}
\hline $\begin{array}{l}\text { Injuries 2017-2018 } \\
\text { (n= 633) }\end{array}$ & $\mathbf{n}$ & $\mathbf{\%}$ & $\begin{array}{l}\text { Injuries 2009-2012 } \\
\text { (n= 911) }\end{array}$ & $\mathbf{n}$ & $\mathbf{\%}$ & $\begin{array}{l}\text { Injuries 1998-2001 } \\
(\mathbf{n = 6 0 4 )}\end{array}$ & $\mathbf{n}$ & $\%$ \\
\hline Pulley injury (finger) & 78 & 12,3 & Pulley injury (finger) & 140 & 15,4 & Pulley injury (finger) & 122 & 20,2 \\
\hline Tenosynovitis (finger) & 67 & 10,6 & Capsulitis (finger) & 87 & 9,5 & Epicondylitis & 51 & 8,4 \\
\hline Capsulitis (finger) & 49 & 7,7 & Tenosynovitis (finger) & 80 & 8,8 & Tenosynovitis (finger) & 42 & 7,0 \\
\hline Knee injury & 45 & 7,1 & SLAP tear & 51 & 5,6 & Strain finger joint capsule & 37 & 6,1 \\
\hline SLAP tear (shoulder) & 37 & 5,8 & Epicondylitis & 50 & 5,5 & Skin abrasions & 34 & 5,6 \\
\hline Impingement (shoulder) & 34 & 5,4 & Impingement (shoulder) & 40 & 4,4 & Back problems & 24 & 4,0 \\
\hline Wrist strain & 22 & 3,5 & Strain finger flexor tendon & 36 & 4,0 & Knee injuries & 14 & 2,3 \\
\hline Epicondylitis & 21 & 3,3 & Dupuytren disease & 30 & 3,3 & Fractures & 14 & 2,3 \\
\hline $\begin{array}{l}\text { Growth plate injuries } \\
\text { (finger) }\end{array}$ & 19 & 3,0 & Strain finger joint capsule & 25 & 2,7 & Capsulitis (finger) & 13 & 2,2 \\
\hline Spinal injuries & 18 & 2,8 & $\begin{array}{l}\text { Ganglion finger flexor } \\
\text { tendon }\end{array}$ & 19 & 2,1 & Ganglion finger flexor & 11 & 1,8 \\
\hline
\end{tabular}




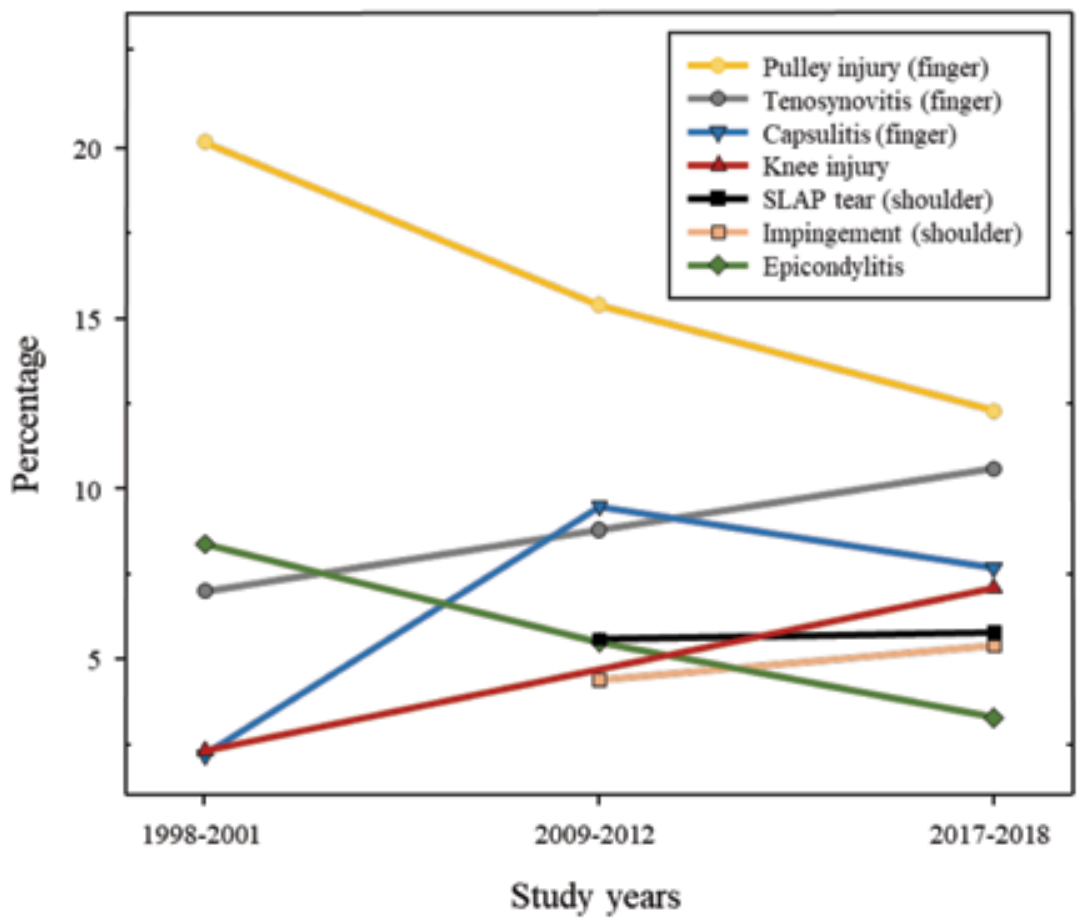

Figure 2. Development of most frequent injuries over the three different survey periods.

Table V. Most frequent finger injuries 2017-2018 ( $n=261), 2009-2012(n=474)$ and 1998-2001 (247).

\begin{tabular}{|c|c|c|c|c|c|c|c|c|}
\hline $\begin{array}{l}\text { Finger injuries } 2017-2018 \\
(n=261)\end{array}$ & n & $\%$ & $\begin{array}{l}\text { Finger injuries } 2009-2012 \\
(n=474)\end{array}$ & n & $\%$ & $\begin{array}{l}\text { Finger injuries 1998-2001 } \\
(n=247)\end{array}$ & $\mathbf{n}$ & $\%$ \\
\hline Tenosynovitis flexor tendon & 67 & 25.7 & Capsulitis & 87 & 18.4 & Tenosynovitis & 42 & 17.0 \\
\hline Capsulitis & 49 & 18.8 & Tenosynovitis flexor tendon & 80 & 16.9 & Strain finger joint capsule & 37 & 15.0 \\
\hline Strain finger joint capsule & 10 & 3.8 & Ganglion finger flexor tendon & 19 & 4.0 & Strain flexor tendon & 7 & 2.8 \\
\hline Osteoarthritis & 5 & 1.9 & Lumbrical shift syndrome & 19 & 4.0 & Fracture & 7 & 2.8 \\
\hline Strain flexor tendon & 4 & 1.5 & Collateral ligament injury & 17 & 3.6 & Osteoarthritis & 7 & 2.8 \\
\hline $\begin{array}{l}\text { Ganglion finger flexor } \\
\text { tendon }\end{array}$ & 3 & 1.2 & Epiphyseal fracture & 16 & 3.4 & Soft tissue injury & 5 & 2.0 \\
\hline Collateral ligament injury & 2 & 0.7 & Lumbrical tear/strain & 4 & 0.8 & $\begin{array}{l}\text { Osseous tear fibrocartilago } \\
\text { palmaris }\end{array}$ & 2 & 0.8 \\
\hline Distorsion thumb & 1 & 0.3 & Snap finger & 3 & 0.6 & Epiphyseal fracture & 2 & 0.8 \\
\hline
\end{tabular}


Table V. Continues

\begin{tabular}{|c|c|c|c|c|c|c|c|c|}
\hline $\begin{array}{l}\text { Finger injuries 2017-2018 } \\
(\mathrm{n}=261)\end{array}$ & $\mathbf{n}$ & $\%$ & $\begin{array}{l}\text { Finger injuries 2009-2012 } \\
(\mathrm{n}=474)\end{array}$ & $\mathbf{n}$ & $\%$ & $\begin{array}{l}\text { Finger injuries 1998-2001 } \\
(n=247)\end{array}$ & $\mathbf{n}$ & $\%$ \\
\hline Disruption volar plate & 1 & 0.3 & Cartilage injury & 2 & 0.4 & Lumbrical tear/strain & 2 & 0.8 \\
\hline Cartilage injury & 1 & 0.3 & Flip phenomena & 2 & 0.4 & Phlegmonia/cellulitis & 1 & 0.4 \\
\hline Neuropraxia & 1 & 0.3 & Broken osteophyte & 1 & 0.2 & Finger amputation & 1 & 0.4 \\
\hline PIP joint dislocation & 1 & 0.3 & Avulsion fracture & 1 & 0.2 & - & - & - \\
\hline Snap finger & 1 & 0.3 & Flexor contraction & 1 & 0.2 & - & - & - \\
\hline $\begin{array}{l}\text { Contracture finger flexor } \\
\text { tendon }\end{array}$ & 1 & 0.3 & Rupture connexus intertend. & 1 & 0.2 & - & - & - \\
\hline- & - & - & Enchondroma & 1 & 0.2 & - & - & - \\
\hline- & - & - & Contusion & 1 & 0.2 & - & - & - \\
\hline- & - & - & Tendon rupture & 1 & 0.2 & - & - & - \\
\hline
\end{tabular}

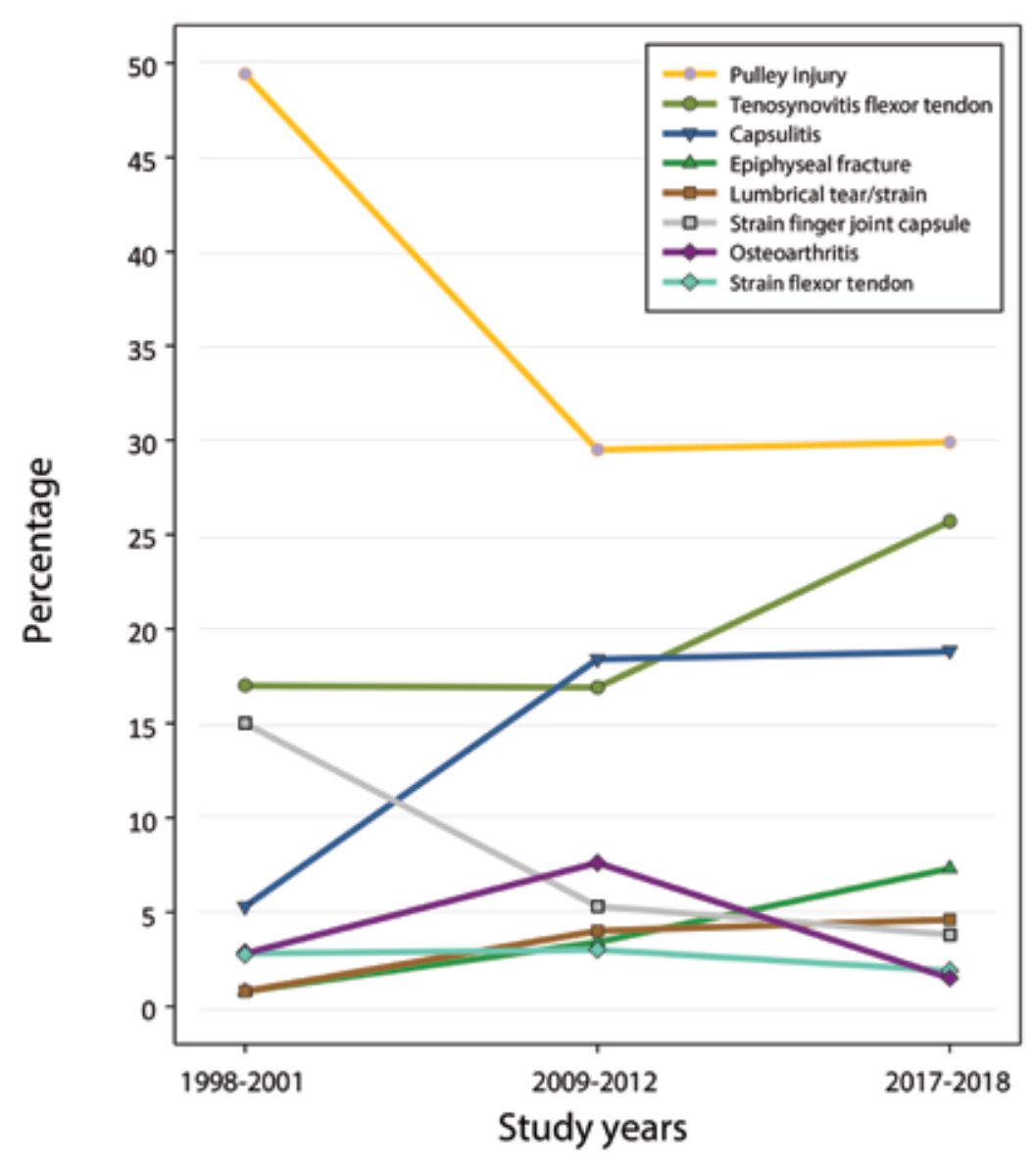

Figure 3. Development of most frequent finger injuries over the three different survey periods. consistent among our three study periods, but a vast scatter over the entire UIAA climbing level scale currently highlights a wide study population. UIAA level one represents the easiest possible climb and UIAA level 12 the world's hardest climbs. Both are represented in the study group.

While most of our patients predominantly climb within the local climbing areas and gyms, several athletes from other regions sought our advice as a second opinion after injuring themselves climbing in other areas. This is consistent with the two prior studies $(14,15)$. The fact that the mean difference in climbing levels among genders was lower than other studies might be explained by the higher percentage of beginners within the current analysis. Male athletes, in general, might have a slightly higher climbing performance potential than female, but gender specific differences are seen less in beginners $(3,5,12,18-22)$. Our data does not allow answering the question whether or not men or female are more risk prone. Self-efficacy and sex differences (higher in males) emerged as important predictors of risk in rock climbing in a psychological analysis (23) and Neuhof et al. (2011) (24) found a higher injury rate (number of 
Table VIII. Distribution of shoulder injuries.

\begin{tabular}{llllll}
\hline Shoulder Injuries 2017-2018 $(\mathbf{n}=\mathbf{1 5 4})$ & $\mathbf{n}$ & $\mathbf{\%}$ & Shoulder Injuries 2009-2012 $(\mathbf{n}=\mathbf{1 5 7})$ & $\mathbf{n}$ & $\mathbf{\%}$ \\
\hline SLAP & 37 & $\mathbf{2 9 . 8}$ & SLAP & 51 & 32.5 \\
\hline Impingement & 34 & 27.4 & Impingement & 40 & 25.5 \\
\hline Dislocation. bankart lesion & 22 & 17.7 & Shoulder sprain & 17 & 10.8 \\
\hline Shoulder sprain & 16 & 12.9 & Dislocation. bankart lesion & 16 & 10.2 \\
\hline Rotator cuff tear & 12 & 9.7 & Supraspinatus tendonitis & 7 & 4.5 \\
\hline Acromioclavicular joint injury & 12 & 9.7 & Instability (non-bankart) & 7 & 4.5 \\
\hline Tendinosis of long biceps tendon & 6 & 4.8 & Tendinosis of long biceps tendon & 5 & 3.2 \\
\hline Instability (non-bankart) & 5 & 4.0 & Rupture of long biceps tendon & 5 & 3.2 \\
\hline Pulley injury & 5 & 4.0 & Rotator cuff tear & 5 & 3.2 \\
\hline Rupture of long biceps tendon & 2 & 1.6 & Acromioclavicular joint injury & 3 & 1.9 \\
\hline Other & 2 & 1.6 & Pulley injury & 1 & 0.6 \\
\hline Supraspinatus tendonitis & 1 & 0.8 & & &
\end{tabular}

injuries divided through 1000 hours of sport participation) for female (0.23) than for male (0.19) climbers $(\mathrm{p}=0.83)$. In contrast, Josephsen et al. (25) found no relation of bouldering injuries to gender, years of climbing, body mass index or weight.

While an overall low injury rate has been described for bouldering in the past $(4,25-29)$, the vast majority of acute injuries in our athletes was found to result from this sub-discipline (30). This fact might be explained by the new wave of beginners that perform indoor bouldering and who were described to be prone to get injured more frequently $(2,31)$. Considering acutely injured athletes generally seek help at the closest medical facility rather than a facility specialized in climbing injuries (15), it must be assumed that acute injuries in both bouldering and rock climbing are underrepresented in our study. This is especially true in cases of fractures or acute ligament injuries. Injuries that are known to result from ground falls during bouldering, rather than from rope protected climbing, are knee injuries and dislocations of the shoulder (both glenohumeral and acromio-clavicular joints). The percentage of knee injuries increased from $2.3 \%(1998-2001)$ to $7.1 \%$ (current study group) while glenohumeral shoulder dislocations and acromioclavicular joint injuries increased from $10.2 \%$ and $1.9 \%$ (2009-2012) to $17.7 \%$ and $9.7 \%$, respectively (tables IV, VI). There could be a slight sample bias, as the authors specialize in sports medicine upper extremity and knee surgery. However, the findings coincide with other recently published studies $(12,17)$. In addition, that sample bias already existed in prior studies, and would therefore not influence a comparison to these data.
The introduction of several preventive strategies (e.g. increase in climber's and coach's awareness on warm up strategies, antagonist training and neglect of certain training strategies, such as pull-ups with uniform hand positioning routines or finger taping) have been established to increase awareness and reduce prevalence of various injury types. Ever since, physical complaints such as pulley injuries and epicondylitis ("climbers' elbow") have decreasingly been detected/diagnosed $(14,15)$. Various associations, such as the British Mountaineering Council (BMC), support and actively promote prevention programs (https://www. thebmc.co.uk/growth-plate-stress-fractures-in-teenageclimbers). Unfortunately, preventive measures have not yet caused a decrease of epiphyseal injuries in adolescent athletes in our current population $(15,32,33)$. Since the first study (1998-2001) a sevenfold increase of this injury type has been observed $(14,15)$ (table V). This increase can partially be explained by the rising numbers of adolescent athletes that goes along with the world-wide climbing and bouldering hype. However, a positive finding among the affected athletes was that none of the 19 patients reported having trained on a campus board training tool, which is known to strongly favor the development of epiphyseal injuries of the finger and showed significance for early osteoarthritis in young climbers (15). The numbers, however, are still alarming and need to be further acknowledged by the national and international climbing community. Precautions need to be implemented and early detection needs to be increased. Even if it may seem as previous work on prophylaxis and knowledge transfer may not have influenced this specific epidemiology, we predominantly see 
these injuries at an earlier, and thus better, treatable stage. Hopefully, increased public awareness will give better treatment options and lead to better outcomes in the future. In this respect, we perform ultrasound scans in young climbers of national, state, and regional teams during our yearly examination (18). During these exams, we evaluate the most vulnerable phase for growth plate fractures, known to be the period just before dorsal closure of the growth plates during their peak growth spurt (34). Climbers and parents are informed about the increased risk and advised to seek immediate consultation in the case of dorsal sided finger pain after climbing that continues for more than one week (35). To avoid epiphyseal stress reactions, load management and recovery must be encouraged, particularly in young athletes which are strongly motivated to incessantly train and climb. It is important to better reach adolescent athletes and their parents, especially those without trainers, to draw attention to the dangers and symptoms growth plate injuries, and to inform them of preventative measures. This is something that even the operators of commercial gyms should be aware of and responsible for.

Our study has some important limitations. The cohort of climbers in this study is diverse, as most of the athletes came from local sport climbing areas or gyms, others came from further away. The kind of climbing predominantly performed in the area may influence the injury profile. This bias is constant throughout all our studies, though (14, 15). The previous studies did not report on specific details about the injury cause, such as the exact climbing activ-

\section{REFERENCES}

1. Lutter C, El-Sheikh Y, Schoffl I, Schoffl V. Sport climbing: Medical considerations for this new olympic discipline. Br J Sports Med. 2017;51:2-3.

2. Schoffl V, Lutter C. The "newbie" syndrome. Wilderness Environ Med. 2017;28:377-380.

3. Schöffl V, Morrison A, Schöffl I, Küpper T. Epidemiology of injury in mountainering, rock and iceclimbing. In: Caine D, Heggie T, eds. Medicine and sport science - epidemiology of injury in adventure and extreme sports. Vol 58: Karger; 2012:17-43.

4. Jones G, Schöffl V, Johnson MI. Incidence, diagnosis, and management of injury in sport climbing and bouldering: A critical review. Curr Sports Med Rep. 2018;17:396-401.

5. Jones G, Asghar A, Llewellyn DJ. The epidemiology of rock climbing injuries. Br J Sports Med. 2007:773-778.

6. Grønhaug G. Self-reported chronic injuries in climbing: Who gets injured when? BMJ Open Sport Exerc Med. 2018;4:e000406. doi: 000410.001136/bmjsem-002018-000406. eCollection 002018.

7. McDonald JW, Henrie AM, Teramoto M, Medina E, Willick SE. Descriptive epidemiology, medical evaluation, and ity (sub-discipline). Therefore, a detailed comparison on injury frequencies among subdisciplines was not possible. A selection bias cannot be dismissed; as we are very active in treating finger, shoulder and knee injuries in climbers, the patient selection is certainly affected. Nevertheless, this bias is also existing in the previous analysis $(36,37)$. Thus, constant re-evaluation is important to show trends in injury development and the effects of preventive measures in this context, the implementation of preventive strategies or training programs should be individually assessed.

\section{CONCLUSIONS}

The analysis of our recently-treated rock-climbing patients revealed several important findings. Overall, low injury severity in rock climbing and bouldering could be confirmed. Bouldering caused more acute injuries than rope-protected climbing. While common rock climbing related diagnosis, such as finger pulley injuries or epicondylitis decreased in frequency, other complaints (e.g. knee injuries) increased significantly. Despite all efforts, epiphyseal finger injuries in young climbers increased further. Therefore, more educational efforts and specific training are necessary to assure an early detection and treatment, thus avoiding long-term consequences.

\section{CONFLICT OF INTERESTS}

The authors declare that they have no conflict of interests (38).

outcomes of rock climbing injuries. Wilderness Environ Med. 2017;28:185-196.

8. Jones G, Llewellyn D, Johnson MI. Previous injury as a risk factor for reinjury in rock climbing: A secondary analysis of data from a retrospective cross-sectional cohort survey of active rock climbers. BMJ Open Sport Exerc Med. 2015;1.

9. Schoffl VR, Hoffmann G, Kupper T. Acute injury risk and severity in indoor climbing-a prospective analysis of 515,337 indoor climbing wall visits in 5 years. Wilderness Environ Med. 2013;24:187-194.

10. Schoffl V, Lutter C, Popp D. The "heel hook"-a climbing-specific technique to injure the leg. Wilderness Environ Med. 2016;27:294-301.

11. Lutter C, Schweizer A, Schoffl V, Romer F, Bayer T. Lumbrical muscle tear: Clinical presentation, imaging findings and outcome. J Hand Surg Eur Vol. 2018;43:767-775.

12. Buzzacott P, Schoffl I, Chimiak J, Schoffl V. Rock climbing injuries treated in us emergency departments, 2008-2016. Wilderness Environ Med. 2019.

13. Schöffl V, Morrison A, Hefti U, Ullrich S, Kupper T. The uiaa medical commission injury classification for mountaineering and climbing sports. Wilderness Environ Med. 2011;22:46-51. 
14. Schoffl V, Hochholzer T, Winkelmann HP, Strecker W. Pulley injuries in rock climbers. Wilderness Environ Med. 2003;14:94-100.

15. Schoffl V, Popp D, Kupper T, Schoffl I. Injury trends in rock climbers: Evaluation of a case series of 911 injuries between 2009 and 2012. Wilderness Environ Med. 2015;26:62-67.

16. Orchard J. Orchard sports injury classification system (osics). Sport Health. 1995;11:39-41.

17. Asakawa D, Sakamoto M. Retrospective survey of sport climbing injuries and self-care in the gunma prefecture. The Journal of Physical Therapy Science. 2019;31:332-335.

18. Schöffl V, Lutter C, Wollings K, Schöffl I. Pediatric and adolescent injury in rock climbing. Res Sports Med. 2018;26:91-113

19. Drapper N, Gilles D, Schöffl V, et.al. Comparative grading scales, statistical analyses, climber descriptors and ability grouping: International rock climbing research association position statement. Sports Technology. 2016.

20. Schöffl V, Popp D, Küpper T, Schöffl I. Injury distribution in rock climbers - a prospective evaluation of 911 injuries between 2009-2012. Wilderness Environ Med. 2015;26:62-67.

21. Schöffl V, Morrison AB, Schwarz U, Schöffl I, Küpper T. Evaluation of injury and fatality risk in rock and ice climbing. Sport Med. 2010;40:657-679.

22. Michailov M, Mladenov L, Schöffl V. Anthropometric and strength characteristics of world-class boulderers. Medicine Sportiva. 2009;2009:231-238.

23. Llewellyn DJ, Sanchez X. Individual differences and risk taking in rock climbers. Psychology of Sport and Exercise. 2008;9:423-426.

24. Neuhof A, F.F. H, I. S, V. S. Injury risk evaluation in sport climbing (in press). Int J Sports Med. 2011.

25. Josephsen G, Shinneman S, Tamayo-Sarver J, et al. Injuries in bouldering: A prospective study. Wilderness Environ Med. 2007;18:271-280.

26. McDonald JW, Henrie AM, Teramoto M, Medina E, Willick SE. Descriptive epidemiology, medical evaluation, and outcomes of rock climbing injuries. Wilderness Environ Med. 2017;28:185-196
27. Woollings KY, McKay CD, Emery CA. Risk factors for injury in sport climbing and bouldering: A systematic review of the literature. Br J Sports Med. 2015;49:1094-1099.

28. Schöffl VR, Hoffmann G, Kupper T. Acute injury risk and severity in indoor climbing-a prospective analysis of 515,337 indoor climbing wall visits in 5 years. Wilderness Environ Med. 2013;24:187-194.

29. Neuhof A, Hennig FF, I. S, V. S. Injury risk evaluation in sport climbing. Int J Sports Med. 2011;32.

30. Josephsen G, Shinneman S, Tamayo-Sarver J, et al. Injuries in bouldering: A prospective study. Wilderness and Environmental Medicine. 2007;18:271-280.

31. Schöffl V, Simon M, Lutter C. Finger- und schulterverletzungen im klettersport (finger and shoulder injuries in rock climbing). Orthopäde. 2019; in press.

32. Bayer T, Schoffl VR, Lenhart M, Herold T. Epiphyseal stress fractures of finger phalanges in adolescent climbing athletes: A 3.0-tesla magnetic resonance imaging evaluation. Skeletal Radiol. 2013;42:1521-1525.

33. Hochholzer T, Schoffl VR. Epiphyseal fractures of the finger middle joints in young sport climbers. Wilderness Environ Med. 2005;16:139-142.

34. Schöffl I, Schöffl V. Epiphyseal stress fractures in the fingers of adolescents: Biomechanics, pathomechanism, and risk factors. European Journal of Sports Medicine 2015;3:27-37.

35. Schöffl I, Lutter C, Schöffl V. What to examine in youth climbing athletes: Yearly examination of the german climbing team and its consequences. Sportverl Sportschad. 2019;In Press.

36. Schöffl V, Hochholzer T, Winkelmann HP, Strecker W. Pulley injuries in rock climbers. Wilderness Environ Med. 2003;14:94-100.

37. Schöffl V, Hochholzer T, Winkelmann HP, Strecker W. [differential diagnosis of finger pain in sport climbers] differentialdiagnose von fingerschmerzen bei sportkletterern. D Z Sportmed. 2003;54:38-43.

38. Padulo J, Oliva F, Frizziero A, Maffulli N. Muscles, Ligaments and Tendons Journal - Basic principles and recommendations in clinical and field Science Research: 2018 update. MLTJ 2018; 8(3): $305-307$. 